\title{
Quilt Pattern Inspired Engineering: Efficient Manufacturing of Shelter Topologies
}

\author{
M.D. Tumbeva, ${ }^{a}$ Y. Wang, ${ }^{a}$ M.M. Sowar, ${ }^{\text {a A.J. Dascanio, }},{ }^{a}$ and A.P. Thrall ${ }^{\mathrm{a},}{ }^{*}$
}

${ }^{a}$ Kinetic Structures Laboratory, Department of Civil \& Environmental Engineering \& Earth Sciences, University of Notre Dame, Notre Dame, IN 46556, USA. *Corresponding author Email addresses: mtumbeva@nd.edu (M.D. Tumbeva),ywang32@nd.edu (Y. Wang), msowar@nd.edu (M.M. Sowar), adascani@alumni.nd.edu (A.J. Dascanio), athrall@nd.edu (A.P. Thrall)

\begin{abstract}
Lightweight, thermally insulated, temporary shelters are essential for disaster relief and military operations. To minimize cost and increase sustainability, it is advantageous to reduce wasted material in manufacturing these shelters. This paper investigates quilt patterns - designs of interlocking geometric shapes - as inspiration for structural topologies that can be manufactured from flat sheets with minimal wasted material (shape interfaces serve as cut and fold lines). A series of quilt-inspired concepts based on established quilt patterns are developed into structural topologies using shape grammar rules. The detailed finite element analysis and design of three concepts is presented. To achieve a lightweight, thermally insulated design, the structures are comprised of sandwich panels (fiber-reinforced polymer faces and a foam core). The performance of each design is compared to an existing rigid wall shelter, demonstrating the efficacy of quilt-inspired forms. This paper is the first investigation of quilting as inspiration for structural systems.
\end{abstract}

\section{Keywords:}

Shelter; Structural Morphology; Manufacturing; Sandwich Panel; Lightweight Structure; Temporary Structure 


\section{Introduction}

Developing lightweight temporary sheltering systems that are thermally insulated is critical for military and disaster relief efforts. Thermal insulation in shelters is an increasing priority for the military due to fuel costs for heating and air conditioning shelters and lives lost in fuel transportation missions. For example, as of 2011, the United States military is spending 66 million USD per day on fuel for air conditioning and over one thousand soldiers have been killed in fuel missions in Iraq and Afghanistan [1]. Furthermore, with an expected five-fold increase in the number of natural and anthropogenic hazards within the next 50 years [2], improved sheltering systems are an increasing humanitarian priority as well. Existing soft wall (canvas) shelters are inexpensive, lightweight, and can be packaged in small volumes for transportation. However, they provide limited thermal insulation. Rigid wall shelters offer high thermal insulation, but are heavy and difficult to transport. In addition, they tend to be box-shaped topologies which are not structurally efficient. See Quaglia et al. [3] for a detailed review of these systems.

Energy efficiency and modeling of temporary sheltering is becoming an increasing area of research (e.g., [4-8]). Toward addressing the challenge of increasing the thermal insulation for temporary shelters, the development of novel shelter topologies is a growing field. Ongoing research activities include investigating the implementation of structurally insulated panels (SIP) for military barracks [9-10]. The art of origami offers inspiration for a wide array of engineering applications [11], particularly for thermally insulated, deployable sheltering topologies as it offers a means for packaging rigid wall shelters in small volumes [12]. Quaglia et al. [3,4] have proposed a viable solution for a deployable origami-inspired shelter with enhanced energy performance that has been experimentally tested [13-14]. This solution is comprised of 
sandwich panels [fiber reinforced polymer (FRP) faces and a foam core] which offer a high strength-to-weight ratio and thermal insulation for energy efficiency in heating and cooling $[4,12]$. When using high cost material such as advanced composites, however, there is an advantage in minimizing wasted material in the manufacturing process. An additional advantage of origami-inspired engineering, is that it is based on using only a single sheet of material, i.e., waste of material in the manufacturing process is minimized. Alternatively, when deployability is not required and a rigid wall sheltering system can simply be erected in-situ from prefabricated panels, the art of quilting can be used as inspiration for novel, structurally efficient topologies that minimize wasted material in manufacturing. More specifically, quilt patterns are carefully designed, interlocking geometric shapes that form a single surface known as a quilt block. The resulting pattern could be utilized as a manufacturing pattern in which shape interfaces serve as lines to cut flat sheets of material.

At the most basic level, a quilt can be defined as being comprised of two pieces of fabric that are stitched together separated by padding. Quilting includes both the art of needlework to stitch independent fabric pieces together and the art of patchwork which determines the shape and colors of pieces to be combined. Quilts can be classified into three categories: pieced, appliqued, and quilted counterpane [15]. Pieced quilts - comprised of fabric pieces cut into prescribed shapes and stitched together [15] - are the focus of this research and it is from the art of patchwork from which the structural topologies will be derived. The history of quilting in the United States and England can be traced to access to Indian calico fabrics and quilts toward the end of the $18^{\text {th }}$ century. These washable cotton fabrics featured new ranges of colors and patterns than were previously available in these regions and stimulated the textile industry to begin making similar fabrics. Any unused pieces of fabric were deemed valuable and were 
saved for quilting. From these early inspirations, quilting was embraced throughout the United States and was adopted as a central activity for $19^{\text {th }}$ century American women. Beyond a fulfilling a functional need, quilts became a means of artistic expression, even being used for political messages. Quilting became a unique, American form of art [16]. Pieced quilt patterns have been developed and evolved over centuries with varying names and attributions [17]. While patterns have been published in various magazines since the early $19^{\text {th }}$ century [17], these patterns developed outside of the traditional framework of authorship, intellectual property, and copyright protection [18]. As a result, the quilt patterns discussed in this paper are not attributed to an author and are referred to by traditional names. This paper will develop structural topologies based on established quilt patterns.

This paper proposes quilt-inspired engineering as a strategy for generative structural design for temporary military or disaster relief sheltering aimed toward manufacturing efficiency. Incorporating manufacturing and constructability priorities in the development of structural forms is an active area of research using many approaches. Topology, shape, and size optimization [19] methodologies are increasingly being developed to consider these priorities, including for example fabrication cost [20], construction cost [21], and manufacturing constraints [22]. Optimization methodologies are also being implemented for the design of modular structures which offer cost-saving through opportunities for mass-production [23]. Alternatively, shape grammars - a formal computational approach to generate geometric forms [24] - can be utilized to develop novel architectural topologies [25]. However, this approach can generate an infinite number of solutions. Shape annealing, in which the simulated annealing optimization algorithm is combined with the computational approach of shape grammars and structural analysis, has been developed as a means of developing efficient forms [26-27]. Highly 
relevant to the energy-related priorities of this research, Granadeiro et al [28] have developed a methodology using shape annealing to achieve energy efficient building envelopes. Szykman and Cagan's [29] approach to generate compact component layouts using shape annealing offers opportunities for manufacturing efficiency. Duarte [30] and Sass [31] have proposed shape grammars toward computer-aided design and digital fabrication. The research presented in this paper uses established quilt patterns and develops a shape grammar approach to transform these two-dimensional patterns into three-dimensional structural topologies.

This paper demonstrates the opportunity for quilt-inspired rigid wall sheltering topologies for temporary military or disaster relief sheltering. Such topologies have the potential for enhanced thermal insulation for energy efficiency in heating and cooling while also minimizing wasted material in manufacturing. Quilt-inspired engineering has successfully been used for novel, integrated mirco-electronic chips with enhanced speed by interconnecting integrated circuits through conductive nodules in a quilt-like manner [32]. This paper is the first investigation of quilt-inspired engineering for structural applications. First, a broad variety of quilt-inspired concepts will be presented and discussed. These concepts are derived from established quilt patterns. Shape grammar rules are developed and implemented to transform these patterns into three-dimensional structural topologies. Then the detailed finite element (FE) analysis and design of three selected concepts is presented. Performance metrics - including weight per area and manufacturing efficiency - for the selected concepts are compared to one another and to an existing rigid wall shelter topology. This paper is the first investigation of using quilt patterns as inspiration for structural systems and ultimately demonstrates the feasibility of this principle. 


\section{Concept Development through Shape Grammar Rules}

Figure 1 (left column) shows several established quilt patterns. The reader is referred to Brackman [17] for comprehensive index of quilt patterns. Three-dimensional structural topologies (Figure 1, right column) can be developed from these patterns using a series of shape grammar rules (Figure 2). The shape grammar rules proposed in Figure 2 can be divided into three categories: (1) two-dimensional rules (Rules 1-4), which alter the initial pattern by adding or subtracting lines and surfaces, (2) a functional rule (Rule 5) which determines the purpose of a surface (for example a wall panel is shown as blue, a roof panel is shown as red, and a window is shown as grey), and (3) three-dimensional rules (Rules 6-8) which dictate how the twodimensional pattern becomes three-dimensional. Scaling is an important consideration related to manufacturability - including both practical limits on size of material utilized and fabrication tools to cut this material - as well as functionality of the shelter (for example related to the desired enclosed volume or head room). A designer should implement constraints on scaling related to these practical limits and design priorities. Figure 3 demonstrates the implementation of these shape grammar rules for the one example form. Figure 1 (middle row) shows the shape grammar rules applied to transform from the established pattern to the three-dimensional concept using the symbols shown in Figure 2. Note that only the three-dimensional rules are shown for simplicity. The following paragraphs will discuss each three-dimensional structural topology in more detail.

Figure $1 \mathrm{~A}$ and Figure 3 is a lean-to like structure based on the Alaska Homestead block. An inclined back wall is supported by two triangular walls. Two wings, attached to the triangular walls, secure the structure to the ground. Loads or ground anchors can be added to these features 
to prevent uplift of the structure under wind loading. Rectangular walls support a flat, extended roof which can serve as a canopy, with applications including bus stops and parks.

Figure 1B, also inspired by the Alaska Homestead block, could serve as a large enclosed shelter. The flat-roofed system is supported by triangular and quadrilateral walls which would need to be secured to the ground.

Figure 1C and 1D, both based on the Album block, follow the lean-to like form of Figure 1A. Varying heights and slopes of roofs are achieved by using the pattern's surfaces in different ways. Both have wings or tabs that can be used for securing the structure to the ground.

Figure 1E, inspired by the Merry Kite block, has a gable roof with inclined wall panels. The structure is supported at points which must be appropriately anchored to the ground. Triangular openings could serve as doors, windows, or ventilation.

Inspired by the Sawtooth Star block, Figure 1F is a flat-roofed system with inclined walls. Triangular walls divide the space, also adding privacy between the four sides. Doors or windows could be cut out of these sections as well.

Finally, the Card Trick design, Figure 1G, can form a cantilevering module. Four of these modules can be combined to form an enclosed structure. Pyramid windows provide light and ventilation. This four module system was selected for further study in Section 3.

Each of these concepts holds promise for lightweight, rigid wall shelters. These are shown here to emphasize the broad range of possible structures that can be inspired by quilt patterns. A designer may begin with any quilt-inspired pattern (see those indexed in Brackman [17]) and develop a three-dimensional topology using the shape grammar rules shown in Figure 2. 


\section{Design and Analysis of Three Selected Concepts}

Three of the quilt-inspired concepts from Figure 1 were selected for more detailed analysis and design: (1) Alaska Homestead (Figure 4), (2) Sawtooth Star (Figure 5), and (3) Card Trick (Figure 6) designs.

\subsection{Geometry and Material Properties}

The selected concepts (Figures 4-6) were scaled (Rule 8 in Figure 2) based on temporary sheltering recommendations from The Sphere Project [33], which requires a ceiling height of 2 $\mathrm{m}$ and $3.5 \mathrm{~m}^{2}$ plan area per person. More specifically, all dimensions of the form were scaled directly from the quilt pattern so that that the roof reaches a height of $2 \mathrm{~m}$ as per this ceiling height requirement. Using this scaling, the Alaska Homestead design (plan area with height exceeding $2 \mathrm{~m}: 20.3 \mathrm{~m}^{2}$ ) can house a family of 5, Sawtooth Star design (plan area with height

exceeding $2 \mathrm{m:} 7.13 \mathrm{~m}^{2}$ ) can house a family of 2, and Card Trick design (four module plan area with height exceeding $2 \mathrm{~m}: 42.5 \mathrm{~m}^{2}$ ) can house a family of 12 . A wider array of geometries is also possible if different scales are utilized for different edges. This paper maintained this simplified approach for demonstration.

To provide a high strength-to-weight ratio and thermal insulation for energy efficiency in heating and cooling each structure was comprised of sandwich panels. For cost efficiency, the faces were assumed to be comprised of $1.27 \mathrm{~mm}$ thick fiber-reinforced polymer (FRP) faces (Vectorply biaxial E-LT 1200-P and double-bias E-BX 1200 e-glass laminate [34], layup: $0^{\circ} / 90^{\circ} / 45^{\circ} /-45^{\circ} /-45^{\circ} / 45^{\circ} / 90^{\circ} / 0^{\circ}$ ) and a foam core (Gurit M80 marine foam [35], thicknesses: Alaska Homestead design $-85.7 \mathrm{~mm}$, Sawtooth Star design $-60.3 \mathrm{~mm}$, Card Trick design $-73.0 \mathrm{~mm}$ ). Experimentally measured material properties according to ASTM standards were used for the 
material properties and are summarized in Table 1 [13]. It is assumed that all panels in a structure are comprised of the same sandwich panels.

\subsection{Analysis and Design Approach}

A linear elastic finite element analysis was performed for each structure using SAP2000 [36]. The sandwich panels were modeled as layered, shell elements with the material properties summarized in Table 1 and the thicknesses discussed in Section 3.1. Mesh refinement studies were preformed for each model to ensure numerical convergence. Panel-to-panel connections were assumed to be moment-resisting. Pinned (free rotation, no translation) boundary conditions were assumed along the perimeter of each structure.

Each structure was analyzed and designed under loads per the United States Army Natick Soldier Research, Development \& Engineering Center Commander's Smartbook Equipment Catalog [37], including dead load (D), wind load (W), and snow load (S, $\left.0.479 \mathrm{kN} / \mathrm{m}^{2}\right)$. The wind loads were applied as per American Society of Civil Engineers (ASCE)/Structural Engineering Institute (SEI) Standard 7-10 [38] with a wind velocity of $29.1 \mathrm{~m} / \mathrm{s}$ [37]. The most conservative exposure category and topographic factors were chosen in the calculation of the wind pressures as the shelters could be placed anywhere. Note that the ASCE/SEI Standard 7-10 procedures used here are intended for regular-shaped buildings. Since these structures are not regularly shaped, a final design may need to include the wind tunnel procedure to identify the wind pressures acting on these structures. However, the methods implemented here are sufficient for this preliminary analysis aimed at demonstrating concept feasibility. ASCE/SEI Standard 7-10 Allowable Stress Design load combinations were used as follows:
1. D
2. $\mathrm{D}+\mathrm{S}$ 
3. $\mathrm{D}+0.6 \mathrm{~W}$

4. $\mathrm{D}+0.75(0.6 \mathrm{~W})+0.75 \mathrm{~S}$

5. $0.6 \mathrm{D}+0.6 \mathrm{~W}$

Global behavior of the structure was evaluated through drift limits and a linear (eigenvalue) buckling analysis. Global drift limits of $\mathrm{H} / 400$, where $\mathrm{H}$ is the story height, were considered under combined dead and wind loads (D+W) per ASCE/SEI Standard 7-10 [38]. The linear (eigenvalue) buckling analysis solved the following equation:

$$
[K-\lambda g(p)] \psi=0
$$

where $\mathrm{K}$ is the stiffness matrix, $\lambda$ is the eigenvalue matrix, $g$ is the geometric stiffness under loads $(p)$, and $\Psi$ is the eigenvector matrix [36] to determine the buckling factor. This factor is the amount by which the applied loads would need to be magnified to cause buckling of the structure. Additional global performance metrics include the total weight per plan area (a measure of structural efficiency), and manufacturing efficiency. Here the manufacturing efficiency is the amount of material used compared to the initial square quilt block.

Local behavior was evaluated by investigating face stress, core shear stress, shear crimping, and face wrinkling under the load combinations considered above. Results were compared with limits summarized here, including a factor of safety of 1.5. Face stress and core shear stress are limited by the ultimate strength of the face $\left(\sigma_{f}\right)$ and the core shear strength $\left(\tau_{c}\right)$ found experimentally (Table 1). Face wrinkling stress limits $\left(\sigma_{w c r}\right)$ are calculated as [39-40]:

$$
\sigma_{w c r}=0.5\left(G_{c} E_{c} E_{f}\right)^{1 / 3}
$$

The shear crimping limit per unit width $\left(P_{b}\right)$ is [39]:

$$
P_{b}=t_{c} G_{c}
$$




\section{Discussion and Comparison to Existing Shelter}

The Alaska Homestead, Sawtooth, and Card Trick concepts were designed using the approach summarized in Section 3.2. Figures 7 - 9 show representative maximum and minimum principal stress distributions for each design and the dominant buckling mode. Global performance metrics - including drift, buckling factor, total weight per plan area, and manufacturing efficiency - are provided in Table 2. For all forms, global drift governed the design. Buckling factors for all forms are high, suggesting sufficient safety from buckling. Local performance metrics related to face and core stresses as well as face wrinkling and shear crimping limit states are provided in Table 3. While peak stress concentrations occur at panel-to-panel connections, boundary conditions, and panel centers (demonstrated for a representative load combination in Figures 7-9), the magnitudes of these stresses are far below the limits. Indeed, stresses and forces for all load combinations are far below the limits.

To evaluate these forms, it is critical to compare them to existing rigid wall sheltering technologies such as the U.S. Army's ISO Shelter, Tactical, Nonexpandable (Figure 10, $2.44 \mathrm{~m}$ by $6.07 \mathrm{~m}$ by $2.44 \mathrm{~m}$, [41]). To make a meaningful comparison, a version of this ISO shelter was designed using the sandwich panel material properties (core thickness: $92.1 \mathrm{~mm}$ ) and the design and analysis approach implemented in the quilt-inspired forms (Section 3.2). Like the quiltinspired forms, global drift governed designed. Table 2 and 3 summarize the global and local metrics, respectively, considered for each of the quilt-inspired forms.

Overall, the Sawtooth Star design had the lowest weight per area (a measure of the structural efficiency) and the highest manufacturing efficiency. The Alaska Homestead and Card Trick designs have comparable weight per area to one another, but the Alaska Homestead featured enhanced manufacturing efficiency in comparison to the Card Trick design. Most notably, all 
three quilt-inspired forms feature significantly lower weight per plan area compared with the ISO shelter design. The enhanced structural efficiency of the quilt-inspired forms can be attributed to the folded plate architecture that results from these forms. These analyses demonstrated the feasibility of each of the quilt-inspired forms and also the enhanced structural efficiency that the can be achieved through these forms as compared to an existing shelter design.

\section{Conclusion}

This paper demonstrated that quilt-inspired shelters have higher structural efficiency than an existing rigid wall military shelter, with the Sawtooth Star design featuring the lowest weight per area and the highest manufacturing efficiency of the three quilt-inspired forms investigated. Limitations of the work presented here include the analysis assumptions (i.e., moment-resisting connections between panels, pinned boundary conditions along the perimeter) used in design which need to be investigated in future experimental studies.

Future work toward addressing these limitations includes experimental testing of momentresisting connections between panels and ground anchorages. The preliminary designs demonstrated here have assumed moment-resisting connections between panels. This assumption plays a major role in the overall behavior and stability of the system, particularly in relation to global drift which governed design. However, achieving a true moment-resisting connection on a physical structure is challenging. Leading manufacturers (e.g., [42]) have proposed various methods of joining sandwich panels that achieve moment-resisting connections known as corner joints. Heimbs and Pein [43] have investigated the bending and shear capacity of three types of corner joints for honeycomb core sandwich panels. Analogous experimental and numerical studies would need to be performed for the angled connections required for these 
quilt-inspired shelters. Furthermore, ground anchorages must be achieved to prevent uplift of these lightweight shelters. Ballard et al. [44] have demonstrated that stakes can be utilized as ground anchorages for lightweight, folding structures comprised of sandwich panels. In this work, additional flanges or angles are added to the load bearing sandwich panels to create a surface into which stakes can be driven. Similar extensions would be necessary for the quiltinspired forms, requiring detailed experimental and numerical studies.

This paper focused on temporary quilt-inspired sheltering topologies for military and disaster relief sheltering. However, it could be applied for a wide variety of structural applications where minimizing material waste in manufacturing is at a premium. This is particularly relevant for high cost material such as advanced composites. Modern manufacturing strategies, such as computerized numerical control $(\mathrm{CNC})$ cutting, are particularly well-suited for quilt-inspired concepts.

\section{Acknowledgements}

This research was supported by the Department of Civil \& Environmental Engineering \& Earth Sciences at the University of Notre Dame. Madalyn Sowar is grateful for the support of the United States Department of Defense Science, Mathematics And Research for Transformation (SMART) Scholarship for Service Program which generously funds her studies. 


\section{References}

[1] Anderson, S.M. Save energy, save our troops; 2011

<http://www.nytimes.com/2011/01/13/opinion/13anderson.html?r=0\&_r=0> [retrieved 05.09.2015]

[2] Thomas, A.S., and Kopczak, L.R. From Logistics to Supply Chain Management: The Path Forward in the Humanitarian Sector. San Francisco, CA: Fritz Institute; 2005.

[3] Quaglia, C.P., Dascanio, A.J., and Thrall, A.P. Bascule shelters: A novel erection strategy for origami-inspired structures. Engineering Structures. 2014; 75: 276-287.

[4] Quaglia, C.P., Yu, N., Thrall, A.P., and Paolucci, S. Balancing energy efficiency and structural performance through multi-objective shape optimization: Case study of a rapidly deployable origami-inspired shelter. Energy and Buildings. 2014; 82: 733-745.

[5] Chaves-Martinez, R.C. and Sen, M. Building energy management: Construction and characterization of an environmental test chamber. Proceedings of the ASME IMECE. Montreal, Canada; 2014.

[6] Salakij, S., Chavez-Martinez, R., Yu, N., Sen, M., Paolucci, S., and Antsaklis, P. Building energy management: Thermal modeling, CFD simulation andsmall-scale experimentation. Proceedings of the ASME IMECE. Montreal, Canada; 2014.

[7] Salakij, S., Yu, N., Paolucci, S., and Antsaklis, P. Building energy management: Optimization using smart model-based control. Proceedings of the ASME IMECE. Montreal, Canada; 2014.

[8] Cornaro, C., Sapori, D., Bucci, F., Pierro, M., and Giammanco, C. Thermal performance analysis of an emergency shelter using dynamic building simulation. Energy and Buildings. 2015; 88: 122-134. 
[9] Severson, B. and St. Leger, A. Feasibility study of photovoltaic panels in military temporary housing structures. Proceedings of the IEEE Green Technologies Conference, Denver, CO; 2013, p. $78-84$.

[10] US Army Corps of Engineers. USMA WP Cadets SIP hut work completes first term; 2012. <http://www.erdc.usace.army.mil/Media/NewsStories/tabid/9219/Article/476453/usma-wpcadets-sip-hut-work-completes-first-term.aspx > [retrieved 05.09.2015]

[11] Peraza-Hernandez, E.A., Hartl, D.J., Malak Jr., R.J., and Lougads, D.C. Origami inspired actives structures: a synthesis and review. Smart Materials and Structures. 2014; 23(9): 094001.

[12] Martinez-Martin, F.J. and Thrall, A.P. Honeycomb core sandwich panels for origamiinspired deployable shelters: multi-objective optimization for minimum weight and maximum energy efficiency. Engineering Structures. 2014; 69: 158-167.

[13] Ballard, Z.C., Thrall, A.P., Smith, B.J., and Casias, C.M. Impact of hinged connectors on sandwich panel behavior. ASCE Journal of Structural Engineering, In press.

[14] Ballard, Z.C., Gerbo, E.J., Thrall, A.P., and Smith, B.J., Behavior of sandwich panels in a deployable structure. ASCE Journal of Structural Engineering, Under review.

[15] Hall, C.A. and Kretsinger, R.G. The Romance of the Patchwork Quilt in America. New York, NY: Bonanza Books; 1935.

[16] Kiracofe, R. The American Quilt. New York, NY: Clarkson Potter; 1993.

[17] Brackman, B. Encyclopedia of Pieced Quilt Patterns. Paducha, KY: American Quilter's Society; 1993.

[18] Halbert, D. Feminist interpretations of intellectual property. Journal of Gender, Social Policy \& the Law. 2006; 14(3): 431-460. 
[19] Bendsoe, M.P. and Sigmund, O. Topology Optimization: Theory, Methods and Applications. New York, NY: Springer; 2004.

[20] Asadpoure, A. Guest, J.K., and Valdevit, L. Incorporating fabrication cost into topology optimization of discrete structures and lattices. Structural and Multidisciplinary Optimization. 2015; 51(2): 385-396.

[21] Zhu, M. Yang, Y., Gaynor, A.T., and Guest, J.K. Considering constructability in structural topology optimization. Proceedings of the ASCE Structures Congress, Boston, MA; 2014.

[22] Stromberg, L.L., Beghini, A., Baker, W.F., and Paulino, G.H. Application of layout and topology optimization using pattern gradation for the conceptual design of buildings. Structural and Multidisciplinary Optimization. 2011; 43(2): 165-180.

[23] Tugilimana, A., Filomeno Coelho, R. and Thrall, A.P. Structural optimization of standardized trusses by dynamic grouping of modules. Proceedings of the World Congress on Structural and Multidisciplinary Optimization, Sydney, Australia; 2015.

[24] Stiny, G. and Gips, J. Shape grammars and the generative specification of painting and sculpture. Proceedings of the International Federation for Information Processing Congress, Ljubljana, Yugoslavia; 1971.

[25] Stiny, G. A generative approach to composition and style in architecture. Proceedings of the International Conference on the Application of Computers in Architecture, Building Design and Urban Planning, Berlin, Germany; 1979.

[26] Cagan, J. and Mitchell, W.J. Optimally directed shape generation by shape annealing. Environment and Planning B: Planning and Design 1993; 20(1): 5-12.

[27] Shea, K. Essay of Discrete Structures: Purposeful Design of Grammatical Structures by Directed Stochastic Search. PhD Dissertation, Carnegie Mellon University; 1997. 
[28] Granadeiro, V., Duarte, J.P., Correia, J.R., and Leal, V.M.S. Building envelope shape design in early stages of the design process: Integrating architectural design systems and energy simulation. Automation in Construction. 2012; 32: 196-209.

[29] Szykman, S. and Cagan, J. Automated generation of optimally directed three dimensional component layout. Proceedings of the ASME $19^{\text {th }}$ Design Automation Conference, Albuquerque, NM. 1993; p. 527-537.

[30] Duarte, J.P. A discursive grammar for customizing mass housing: the case of Siza's houses at Malagueira. Automation in Construction. 2005; 14: 265-275.

[31] Sass, L. A wood frame grammar: A generative system for digital fabrication. International Journal of Architectural Computing. 2009; 4(1): 51-67.

[32] Bernstein, G.H., Liu, Q., Yan, M., Kopp, D., Porod, W., Snider, G., and Fay, P. Quilt Packaging: High-Denisty, High-Speed Interchip Communications. IEEE Transactions on Advanced Packing 2007; 30(4): 731-740.

[33] Anonymous, The Sphere Project: Humanitarian Charter and Minimum Standards in Humanitarian Response, Rugby, UK: Practical Action; 2011.

[34] Vectorply - Performance Composite Reinforcements. Laminated properties and packaging; 2002. <http://www.vectorply.com/ri-laminateprop.html> [retrieved April 13, 2015].

[35] Gurit. Corecell m-foam - the marine foam; 2013. <http://www.gurit.com/files/documents/corecell-m-foamv5pdf.pdf> [retrieved 09.10.13].

[36] Computers \& Structures, Inc. SAP 2000; 2011, version 15.1.0. <http://www.csiamerica.com/sap2000> [retrieved 04.16.2015]. 
[37] U.S. Army Natick Soldier Research, Development and Engineering Center. Commander's smartbook equipment catalog; 2009.

<nsrdec.natick.army.mil/media/print/Smartbook_Web.pdf> [retrieved 05.23.2015].

[38] American Society of Civil Engineers/Structural Engineering Institute. Minimum design Loads for Buildings and Other Structures (ASCE/SEI Standard 7-10). Reston, VA; 2010.

[39] Hexcel Corporation. HexWeb honeycomb sandwich design technology; 2000.

< http://www.hexcel.com/Resources/DataSheets/Brochure-Data-Sheets/

Honeycomb_Sandwich_Design_Technology.pdf>[retrieved 05.23.2013].

[40] Plantema, F.J. Sandwich Construction: The Bending and Buckling of Sandwich Beams, Plates, and Shells. New York: Wiley; 1966.

[41] Joint Committee on Tactical Shelter. Department of defense standard family of tactical shelters (rigid/soft/hybrid). US Army Natick Soldier Researcher, Development, and Engineering Center, Natick, MA; 2012.

[42] Hexcel Composites. Sandwich panel fabrication technology; 2001 $<$ http://www.hexcel.com/Resources/DataSheets/Brochure-DataSheets/Sandwich_Panel_Fabrication_Technology.pdf> [retrieved 07.21.2015].

[43] Heimbs, S. and Pein, M. Failure behavior of honeycomb sandwich corner joints and inserts. Composite Structures. 2009; 89(4): 575-588.

[44] Ballard, Z.C., Thrall, A.P., and Smith, B.J. Behavior of foldable sandwich panel structures: Impact of ground conditions, anchorage, and panel warping. Construction and Building Materials, Under Review. 
Table 1. Measured material properties for a sandwich panel previously tested by the authors. Data courtesy of Ballard et al. [13].

\begin{tabular}{|l|c|c|}
\hline \multicolumn{1}{|c|}{ Property } & Face & Core \\
\hline Density, $\rho\left(\mathrm{kg} / \mathrm{m}^{3}\right)$ & 1740 & 85.3 \\
\hline Elastic Modulus, $E(\mathrm{MPa})$ & 15500 & 57.7 \\
\hline Ultimate Strength, $\sigma(\mathrm{MPa})$ & 283 & 1.25 \\
\hline Poisson's Ratio, $v$ & 0.261 & -- \\
\hline Shear Modulus, $G(\mathrm{MPa})$ & -- & 47.2 \\
\hline Shear Strength, $\tau(\mathrm{MPa})$ & -- & 1.56 \\
\hline
\end{tabular}

Table 2. Evaluation of global behavior of forms, including global drift, buckling factor, weight per area, and manufacturing efficiency (quantified as the ratio of the selected surfaces to the original quilt pattern).

\begin{tabular}{|c|c|c|c|c|}
\hline Form & Drift/Limit & $\begin{array}{c}\text { Buckling } \\
\text { Factor }\end{array}$ & $\begin{array}{c}\text { Weight/Area } \\
\left(\mathrm{kN} / \mathrm{m}^{2}\right)\end{array}$ & $\begin{array}{c}\text { Manufacturing } \\
\text { Efficiency }\end{array}$ \\
\hline $\begin{array}{l}\text { Alaska } \\
\text { Homestead }\end{array}$ & 0.978 & 175 & 0.231 & 0.840 \\
\hline Sawtooth Star & 0.986 & 271 & 0.178 & 0.875 \\
\hline Card Trick & 0.970 & 69.5 & 0.260 & 0.750 \\
\hline ISO Shelter & 0.957 & 269 & 0.466 & NA \\
\hline
\end{tabular}

Table 3. Evaluation of local behavior of forms, including face stress, face wrinkling, shear core stress, and shear crimping. A safety factor of 1.5 is included.

\begin{tabular}{|l|c|c|c|c|}
\hline \multicolumn{1}{|c|}{ Form } & $\begin{array}{c}\text { Face Stress: } \\
\boldsymbol{\sigma} / \boldsymbol{\sigma}_{\mathbf{y}}\end{array}$ & $\begin{array}{c}\text { Face Wrinkling: } \\
\boldsymbol{\sigma} / \boldsymbol{\sigma}_{\mathbf{c r}}\end{array}$ & $\begin{array}{c}\text { Shear Core } \\
\text { Stress: } \boldsymbol{\tau} / \boldsymbol{\tau}_{\mathbf{c}}\end{array}$ & $\begin{array}{c}\text { Shear } \\
\text { Crimping: } \mathbf{P} / \mathbf{P}_{\mathbf{b}}\end{array}$ \\
\hline Alaska Homestead & 0.035 & 0.057 & 0.011 & 0.005 \\
\hline Sawtooth Star & 0.020 & 0.032 & 0.003 & 0.001 \\
\hline Card Trick & 0.020 & 0.033 & 0.002 & 0.002 \\
\hline ISO Shelter & 0.021 & 0.035 & 0.003 & 0.003 \\
\hline
\end{tabular}




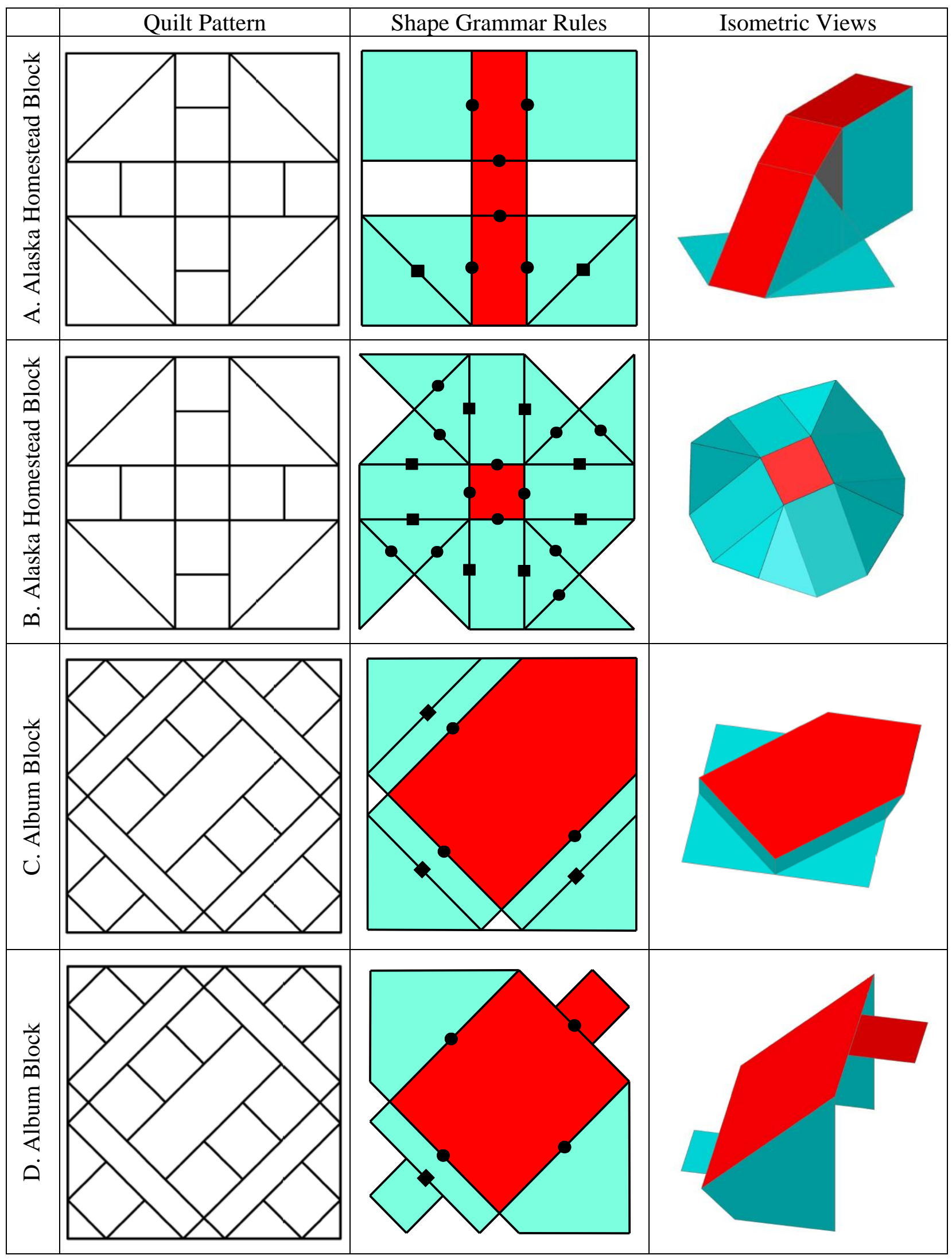




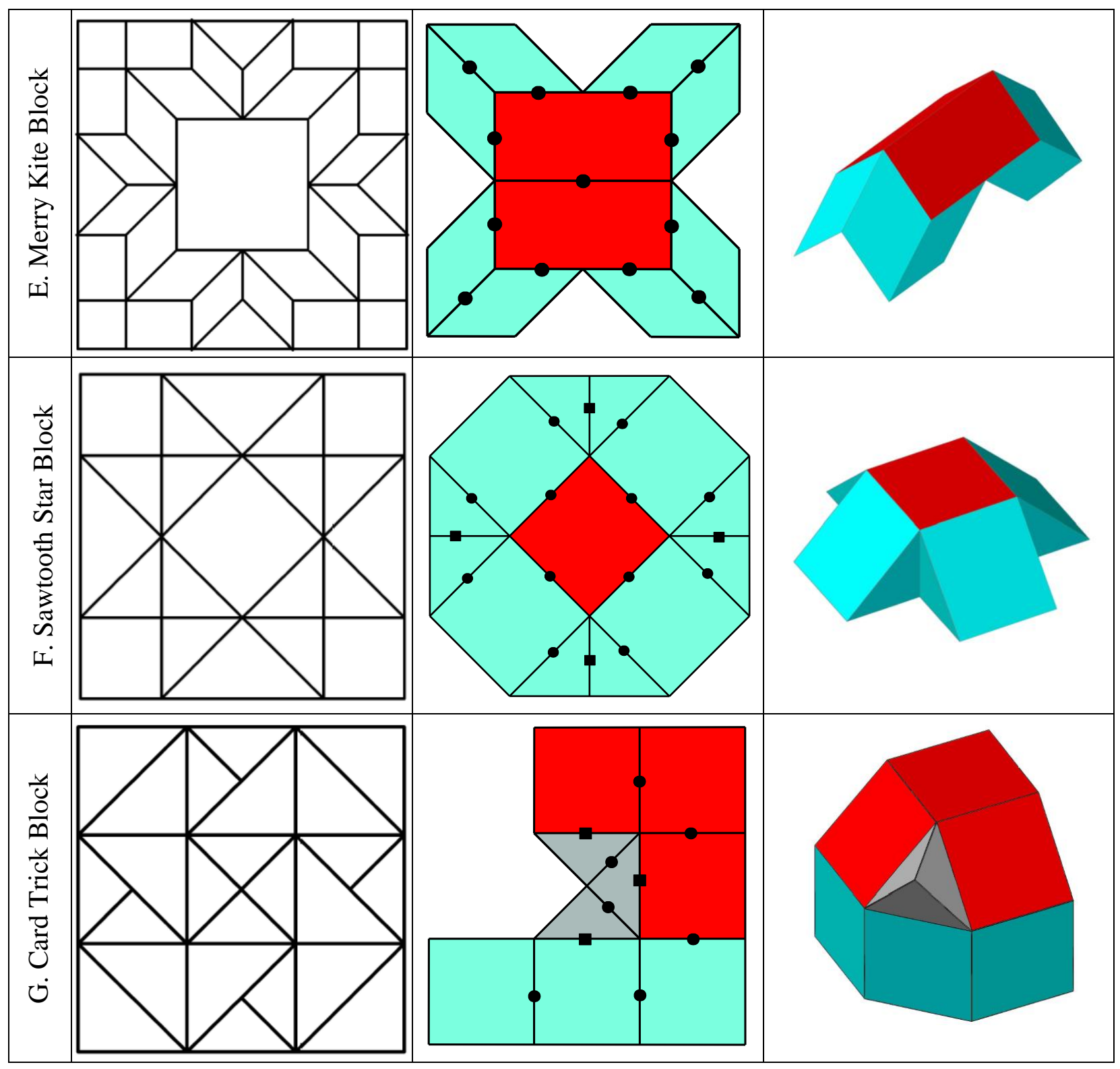

Figure 1. Quilt-inspired concepts, including the established quilt pattern (including name), functional and three-dimensional shape grammar rules implemented (two-dimensional rules not shown for simplicity), and isometric views of the three-dimensional structures. 
Rule 1: Substraction of Line

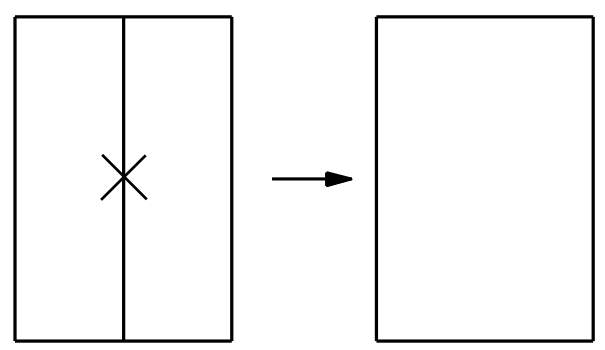

Rule 3: Substraction of Surface

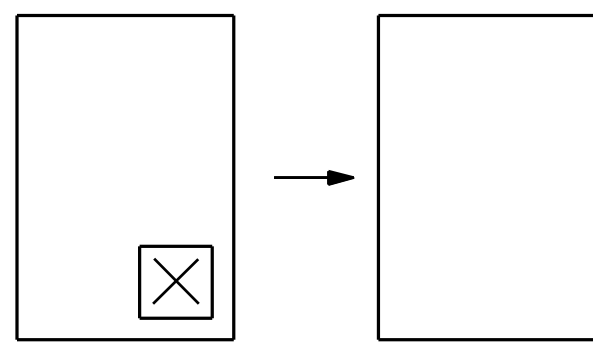

Rule 5: Assignment of Suraface

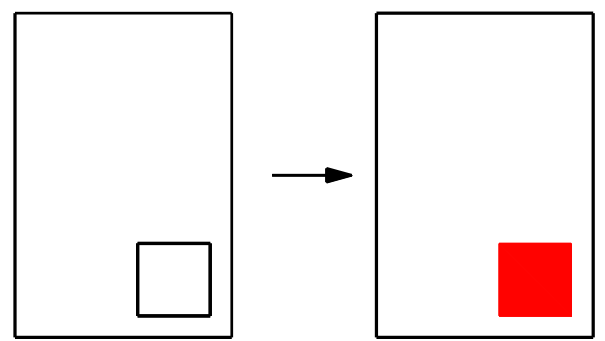

Rule 7: Valley Fold

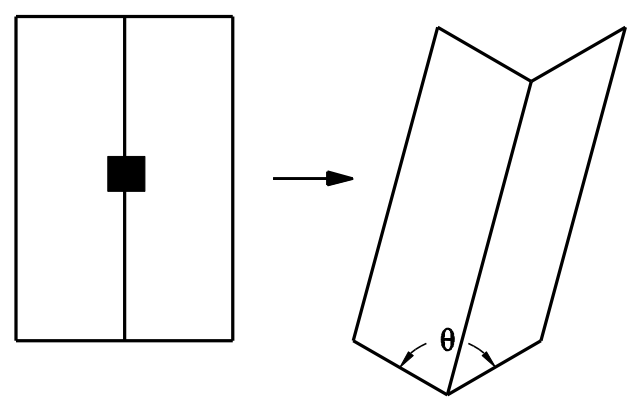

Rule 2: Addition of Line

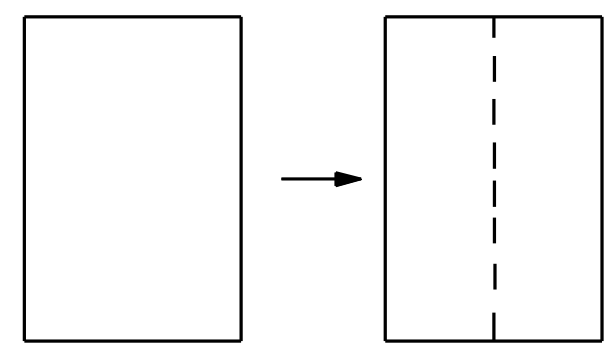

Rule 4: Addition of Surface

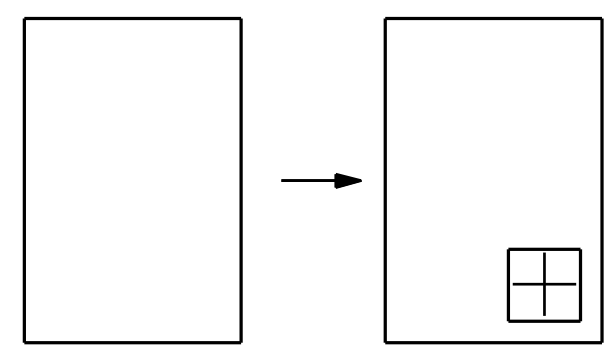

Rule 6: Mountain Fold
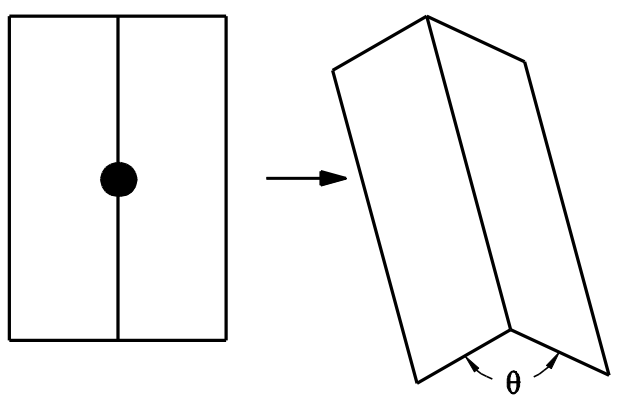

Rule 8: Scale

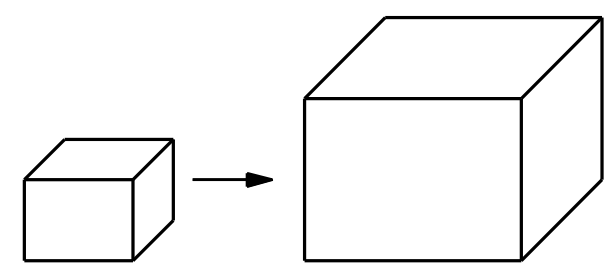

Figure 2. Shape grammar rules to develop quilt-inspired three-dimensional concepts from established patterns including: (1) two-dimensional rules (Rules 1-4) which alter the initial pattern by adding or subtracting lines and surfaces, (2) a functional rule (Rule 5) which determines the purpose of a surface (e.g., wall, roof, window), and (3) three-dimensional rules (Rules 6-8) which dictate how the two-dimensional pattern becomes three-dimensional. 


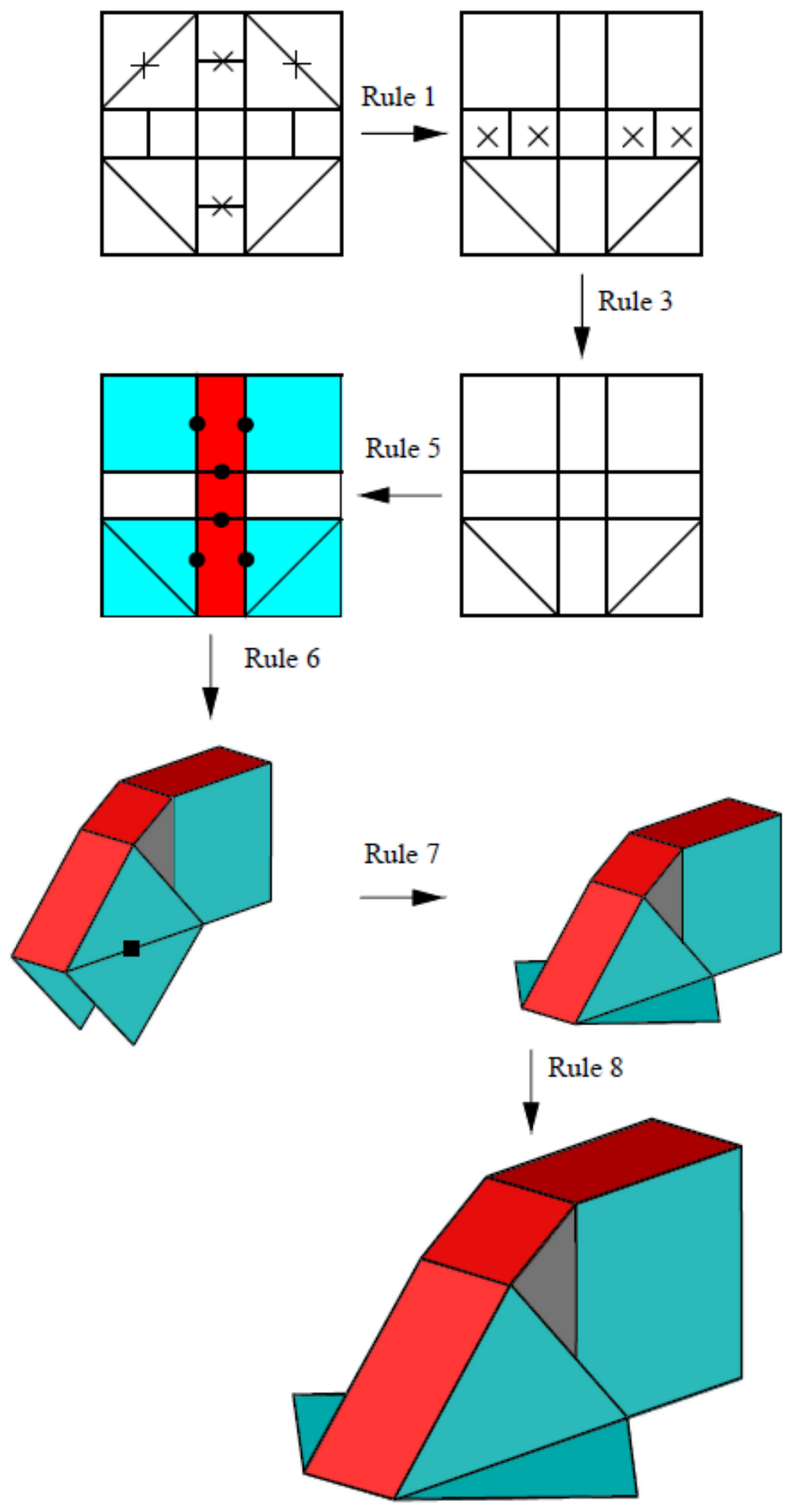

Figure 3. Example demonstration of the implementation of shape grammar rules to arrive at a three-dimensional concept from an established pattern (Figure 1, row 1). 


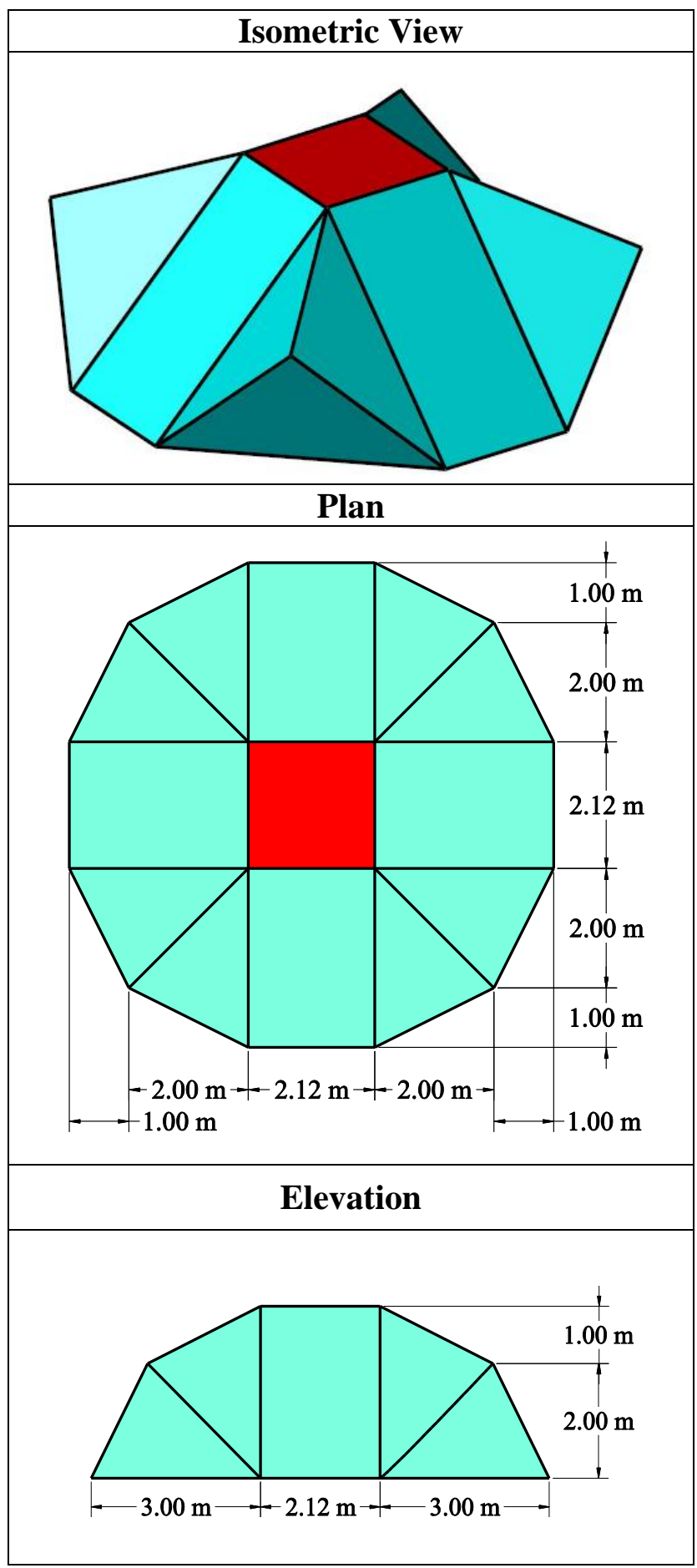

Figure 4. Alaska Homestead design, including isometric, plan, and elevation views. 


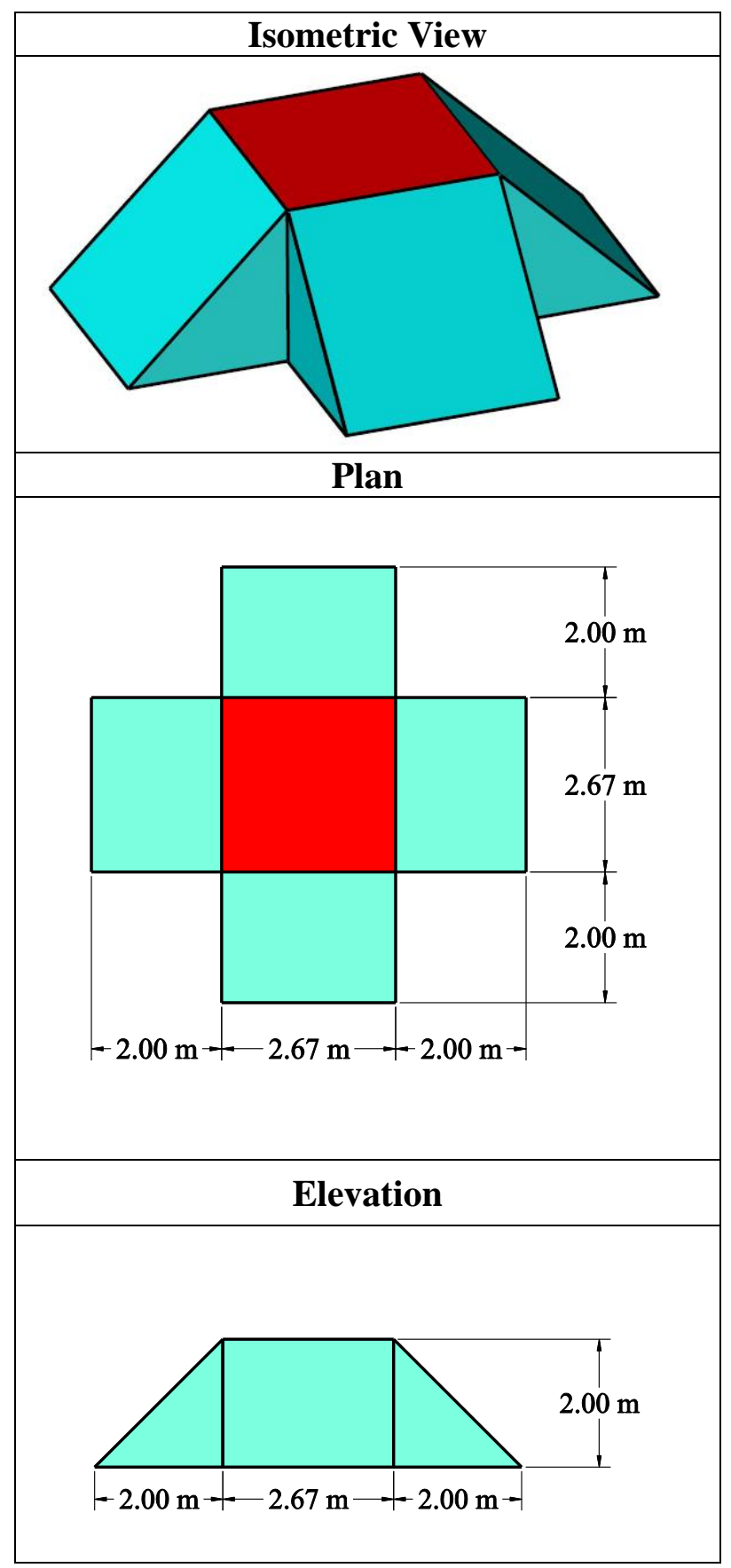

Figure 5. Sawtooth Star design, including isometric, plan, and elevation views. 


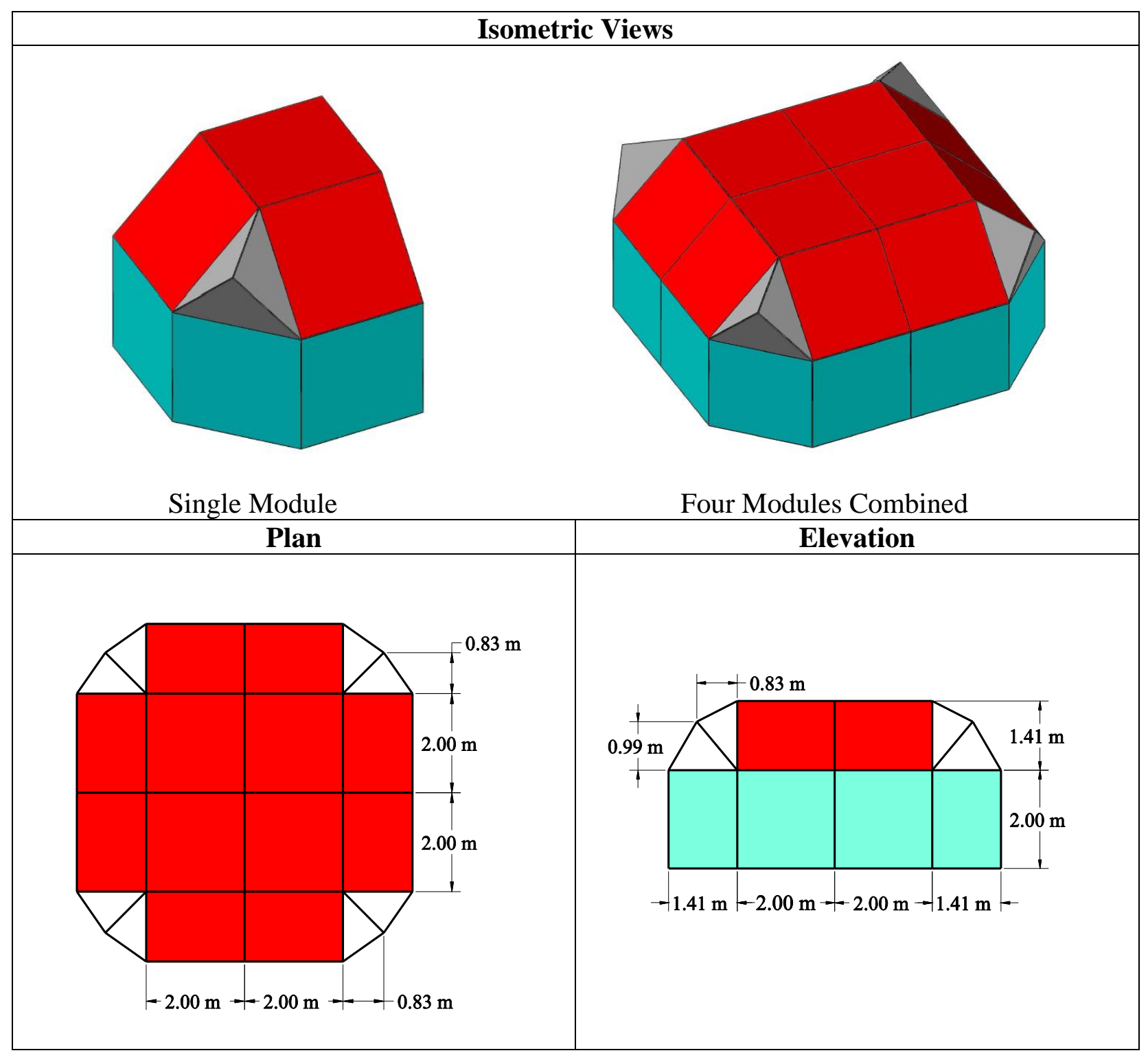

Figure 6. Card Trick design, including isometric, plan, and elevation views. 


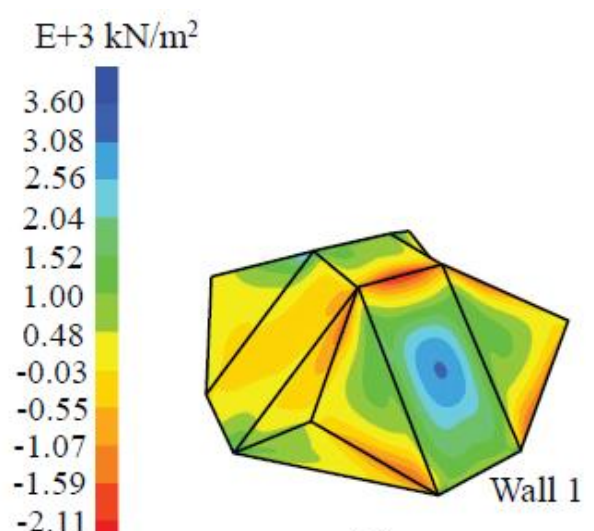

(a)

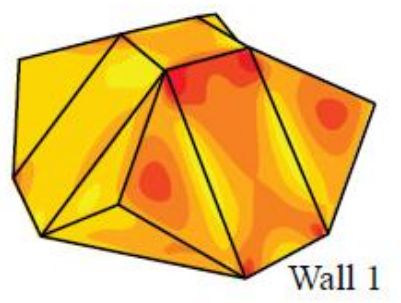

(b)

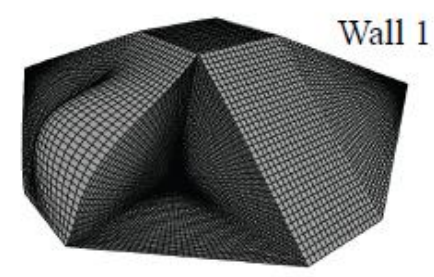

(c)

Figure 7. Alaska Homestead design: Maximum principal stresses on inner face (a) and minimum principal stresses on outer face (b) under load combination $\mathrm{D}+0.75(0.6 \mathrm{~W})+0.75 \mathrm{~S}$ (Wall 1 is windward wall); governing buckling mode (c) corresponding to load combination $0.6 \mathrm{D}+0.6 \mathrm{~W}$. Negative indicates compression, positive indicates tension.

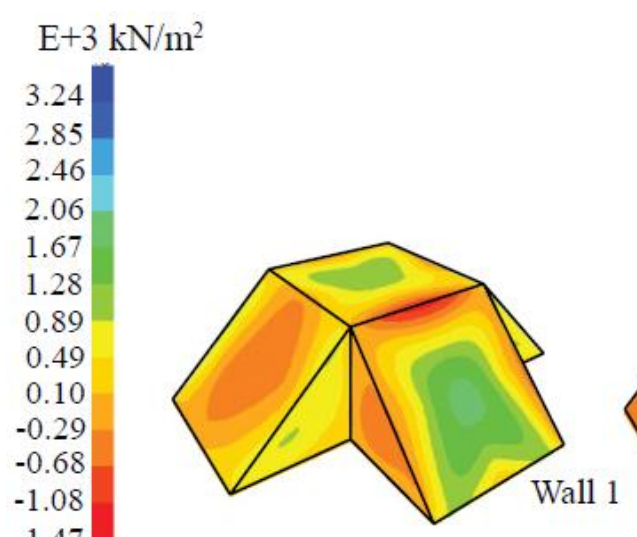

(a)

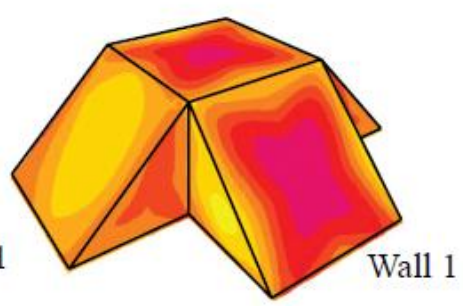

(b)

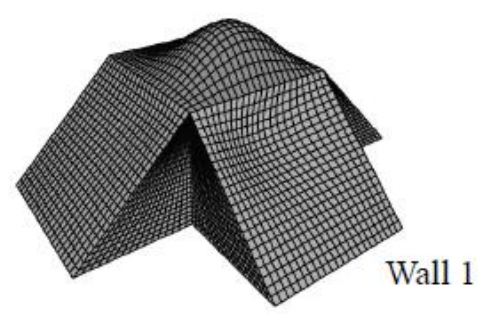

(c)

Figure 8. Sawtooth Star design: Maximum principal stresses on inner face (a) and minimum principal stresses on outer face (b) under load combination $\mathrm{D}+0.75(0.6 \mathrm{~W})+0.75 \mathrm{~S}$ (Wall 1 is windward wall); governing buckling mode (c) corresponding to load combination D + $0.75(0.6 \mathrm{~W})+0.75 \mathrm{~S}$. Negative indicates compression, positive indicates tension. 


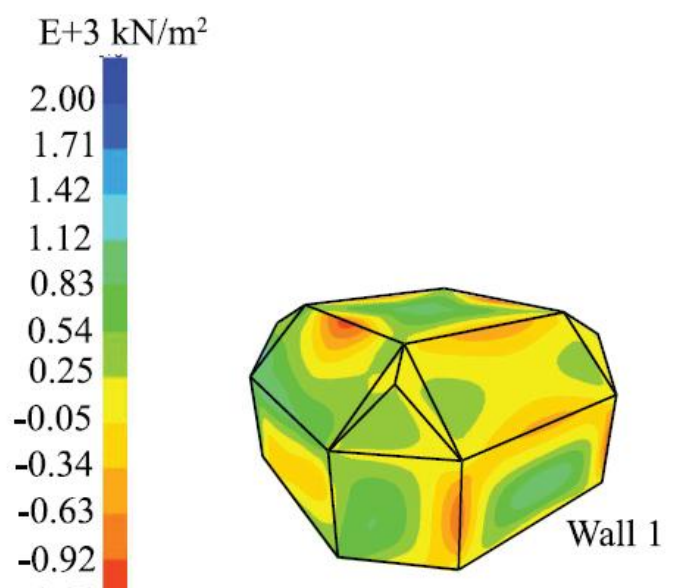

$-1.22$

$-1.51$

$-1.80$

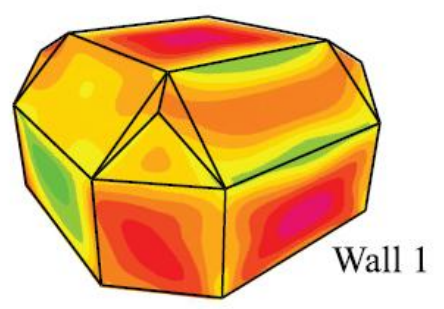

(b)

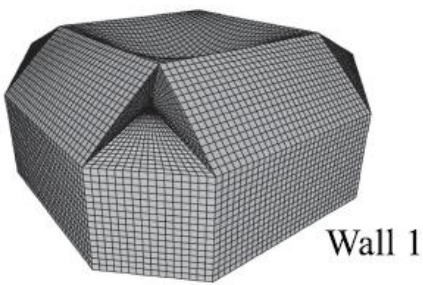

(c)

Figure 9. Card Trick design: Maximum principal stresses on inner face (a) and minimum principal stresses on outer face (b) under load combination $D+0.75(0.6 \mathrm{~W})+0.75 \mathrm{~S}$ (Wall 1 is windward wall); governing buckling mode (c) corresponding to load combination $\mathrm{D}+\mathrm{S}$. Negative indicates compression, positive indicates tension.

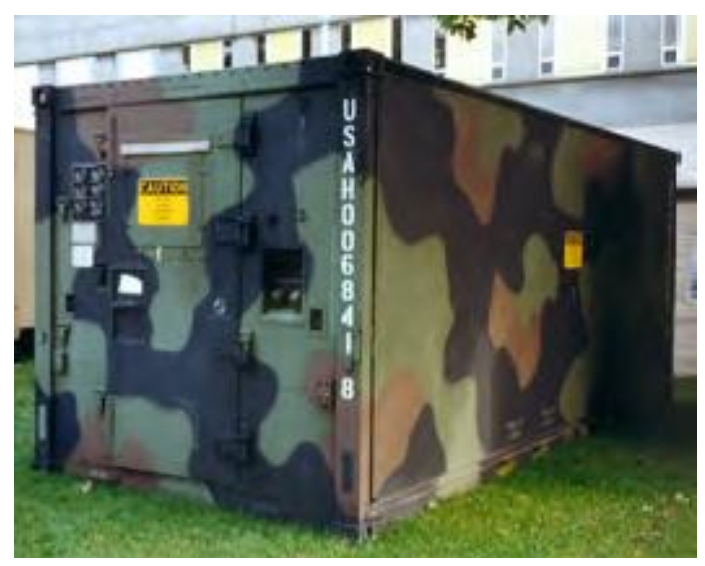

Figure 10. ISO Shelter, Tactical, Nonexpandable. Image courtesy of US Army Natick Soldier Researcher, Development, and Engineering Center [41]. 